\title{
Pyrolysis of carbonaceous particles and properties of Carbonaceous-g- Poly (acrylic acid-co-acrylamide) superabsorbent polymer for agricultural applications
}

\author{
S. Ghazali, S. Jamari, N. Noordin and K. M. Tan
}

Faculty of Chemical and Natural Resources Engineering, Universiti Malaysia Pahang, 26300 Gambang Kuantan, Pahang, Malaysia

\begin{abstract}
Utilisation of fertilizer and water are very important in determining the production of agriculture nowadays. The excessive use of fertilizer in plantation somehow could leads to environmental pollution. The present study reported a synthesis of controlled release water retention (CRWR) fertilizer coating with superabsorbent polymer (SAPs). Superabsorbent polymer (SAPs) are polymers that have ability to absorb and retain large amounts of water relative to their own mass. The presence of coating layer of SAPs on fertilizer granules was believed could reduce excessive used of fertilizer by controlling their dissolution rates and also reduce the environmental pollution. In this study, the effect on the addition of carbonaceous filler in SAPs on the water absorbency was also be compared with control SAPs (without carbonaceous particles). In this study, the carbonaceous filler were obtained from pyrolysis process of empty fruit bunch (EFB) biomass. The synthesized of SAPs and carbonaceous-SAPs were carried out via solution polymerization technique by using monomer of poly(acrylic acid) (AA), acrylamide (AM), cross linker, methylene bisacrylamide (MBA) and initiator, ammonium peroxodisulfate (APS) that partially neutralized with sodium hydroxide $(\mathrm{NaOH})$. The CRWR fertilizer was later be prepared by coated the fertilizer granule with SAPs and carbonaceous-SAPs. The water absorbency, morphology and the bonding formation of both CRWR fertilizer were investigated by using tea-beg method, Scanning Electron Microscopy (SEM) and Fourier Transform Infrared Spectrophotometer (FTIR), respectively. Moreover, the water retention studies was conducted in order to investigate the efficiency of CRWR coated with SAP and carbonaceous-SAP in retaining the water content in different soil (organic and top soil). Based on the results, the CRWR fertilizer that was coated with carbonaceous-SAP had higher water absorbency value than the CRWR fertilizer without carbonaceous-SAP. Meanwhile, $1 \mathrm{wt} \%$ CRWR fertilizer in organic soil gave higher water retention ability compared with $1 \mathrm{wt} \%$ CRWR fertilizer in top soil. In conclusion, CRWR fertilizer coated with carbonaceous filler gave a significant influence on the water absorbency and in controlling the nutrients release rate as well as function as water retention in soil.
\end{abstract}

\section{Introduction}

The agriculture sector plays an important role in economic development, uplifting rural incomes and help in ensuring national food security [1]. Internationally agriculture has become the centre of cutting-edge reaserach and development (R\&D) as the drive to feed and cope with global population. In general, the main factors that affect the growth of plants and their quality are quantity of water and fertilizers that can be absorb by plants. Besides maintaining the water resources, the used of fertilizer is also crucial as it function as one of the nutrients sources for plant in order to achieve maximum efficiency and highest quality product. In order to increase the production, excessive fertilizers are normally were practiced in agricultural activities in order to fulfill and the required nutrients as it will subsequently affect the quality of yield [2]. This practice however is not efficient as not all the nutrients from these fertilizers will be absorbed by the plant because it will be washed or leached out during rain [3]. It has been reported by AlZahrani [4] that only $30 \%$ of the fertilizers are used and utilize by plants while the balance is lost to environment. In order to increase the production, excessive fertilizers are normally were practiced in agricultural activities in order to fulfill and the required nutrients as it will subsequently affect the quality of yield [2]. Beside of the increasing of productive cost, excessive use of fertilizers also causes a negative impact especially on the environment because some fertilizers does contains heavy metals such as cadmium, chromium and high concentrations of radionuclides [2].

The loss of fertilizer will cause large economic losses and environmental pollution [5]. One of the solutions is by applying controlled release fertilizer in agricultural activities to enhance the quality and yield of product. Recently, the use of slow release fertilizer is a new trend to save fertilizer consumption and to minimize environmental pollution [6]. Practically, the factors that controlling the release of the fertilizers include 
temperature, microbial activity, soil moisture, $\mathrm{pH}$ and organic matter. The present study proposed a fabrication of controlled release water retention (CRWR) fertilizer that coated with superabsorbent polymer material. CRWR fertilizer is known as fertilizer that was coated with superabsorbent polymer (SAPs) which was design to control the nutrients release from fertilizer and enhance the efficiency of nutrients use for plant growth [7]. According to Liu \& Guo [8], SAPs can be defined as a long chains polymer which are slightly cross-linked that has ability to swell and maintain bulky of water and aqueous solutions after absorb. In agricultural uses, higher water-holding capacity and nutrient retention in soils is important as it can increase the soil's aeration and microbial activity, reduce the environmental impact from water-soluble fertilizers and lower frequency of irrigation [9].

Moreover, the use of biochar for agricultural application had attracted many attention and recent studies have focused on the application of biochar to soils for carbon storage and soil fertilization [10]. The application of biochar has a number of specific function in the natural environment as it is beneficial to prevent global warming and increases the functionality of soils. Carbon from biochar have the ability to improve the physical properties; by increasing the cation exchange capacity (CEC) and water-holding capacity, of soil [11]. Pyrolysis is the best known method to produce biochar as it is much environmental friendly. Pyrolysis of the biomass feedstocks enables the biomass conversion to biochar whose subsequent application to soil is in a more stabilized form [12]. The pyrolysis process requires less of the supplied fuel than traditional combustion.

This present study reported the pyrolysis process of biochar, solution polymerization process of SAPs and carbonaceous-SAPs to be coated as CRWR fertilizer, and influence of these coating materials on the water absorbency, release behavior and water retention properties of the CRWR fertilizer in different types of soils.

\section{Materials and methods}

\subsection{Pyrolysis of carbonaceous particles}

Pyrolysis of carbonaceous particles was carried out using biomass of empty fruit bunch (EFB) using Nabertherm furnace with nitrogen gas. During the process, the nitrogen gas flow rate was set at $250 \mathrm{ml} / \mathrm{min}$ to purge out the presence of oxygen inside the furnace. This pyrolysis process was carried out at $350^{\circ} \mathrm{C}$ for $1 \mathrm{~h}$ with heating rate of $10^{\circ} \mathrm{C} / \mathrm{min}$. The obtained carbonaceous particles were collected and characterized for moisture content, ash content, volatile content, and calorific value.

\subsection{Synthesis of SAP and carbonaceous-SAP}

In this study, acrylic acid (AA) and acrylamide (AM) that acts as monomer and co-monomer, respectively were neutralized with $\mathrm{NaOH}$ and distilled water in $250 \mathrm{~mL}$ three neck flasks equipped with stirrer, condenser, nitrogen line and thermometer. MBA acts as a crosslinker agent was added in the monomer solution and was stirred at room temperature until the MBA was completely dissolved. The flask then was immersed in a water bath and heated up to $70{ }^{\circ} \mathrm{C}$ and then APS initiator was added to the solution that was magnetically stirred at $300 \mathrm{rpm}$ [13]. The reaction mixture was left to stir for 2 hours until gel point before the resulting hydrogel was removed from the reaction and dried overnight in oven at $60{ }^{\circ} \mathrm{C}$. In prepration of carbonaceous-SAP, same procedure was repeated with addition of $0.5 \mathrm{wt} \%$ of carbonaceous particles that obtained from pyrolysis process was used as filler. Finally, the commercial fertilizer granule were dipped in starch solution and then immediately placed on the prepared SAPs and carbonaceous-SAPs powder to form CRWR fertilizer. The CRWR fertilizer then was dried in oven at $60^{\circ} \mathrm{C}$ to obtain the final product of CRWR fertilizer.

\subsection{Water Absorbency Properties}

In order to determine the water absorbency properties, about $2 \mathrm{~g}$ of sample of SAPs and carbonaceous-SAPs were put in a tea bag $\left(M_{0}\right)$ was immersed in $500 \mathrm{~mL}$ tap water and allowed to soak at room temperature up to $7 \mathrm{~h}$. Then, the immersed tea bags were taken out from water for every certain time and weighted $\left(M_{1}\right)$. The water absorbency $(W A)$ was calculated using the Equation 1 [14]:

$$
W A=\frac{M_{1}-M_{0}}{M_{0}}
$$

\subsection{Water Retention Properties of CRWR in soil}

The water retention of CRWR fertilizer in soil was determined by mixed the CRWR fertilizer in soil for a certain period of time. In this step, $2 \mathrm{~g}$ of CRWR fertilizer was well mixed with $200 \mathrm{~g}$ of soil (ratio 1:100) and kept in a beaker. Then $120 \mathrm{~mL}$ of tap water was slowly added into the beaker and weighed $\left(W_{1}\right)$ and maintained at room temperature. In this step, the control (fertilizer without any coating material) was also being observed for comparison purposed. The beakers that contained fertilizer and soil were weighed every 2 days $(W)$ over a period of 21 days. The water retention ratio $(W R \%)$ of soil was calculated using the Equation 2 [15]:

$$
W R \%=\frac{W}{W_{1}} X 100
$$

\subsection{Fourier Transform Infrared (FTIR) Spectrophometer}

The chemical structure of the SAP samples was established using FTIR spectroscopy. FTIR spectra (thermo, Nicolet, NEXUS, TM) of the samples were taken in $\mathrm{KBr}$ pellets. 


\subsection{Morphological Properties of SAP and CRWR}

The surface morphology of the sample was observed by using Field Emission Scanning Microscope (JSM-5610 LV SEM). The sample is sputter-coated with a gold layer in a vacuum using an Emitech K550 Sputter Coater, prior to analysis.

\section{Result and discussions}

\subsection{Pyrolysis of carbonaceous particles}

The efficiency of any future energy application process depends on the calorific value of the inlet, where high calorific value will increase the amount of energy released. In addition to calorific value, other important properties are moisture content, ash content and volatile content. Energy source that have high calorific value, low moisture content and low ash content can be burned without additional fuel, whereas materials with low calorific value, high moisture content and high ash required supplementary fuel. Analysis to determine the calorific value, moisture content, ash content and volatile content is called a proximate analysis. Fig. 1 depicted proximate analysis of carbonaceous particles that obtained from pyrolysis process. The decomposition mechanism of pyrolysis involves a significant dehydration as the changes in the $\mathrm{H}: \mathrm{C}$ and $\mathrm{O}: \mathrm{C}$ atomic ratios of biomass follows the dehydration pathway. The higher loss in oxygen and hydrogen compared to carbon is highly related to the increase in energy value of the biomass. Compared to oxygen and hydrogen, the bonds between carbon atoms are more stable. Therefore, more energy is needed to break the carbon bond, which will reduce the ability of the combustion.

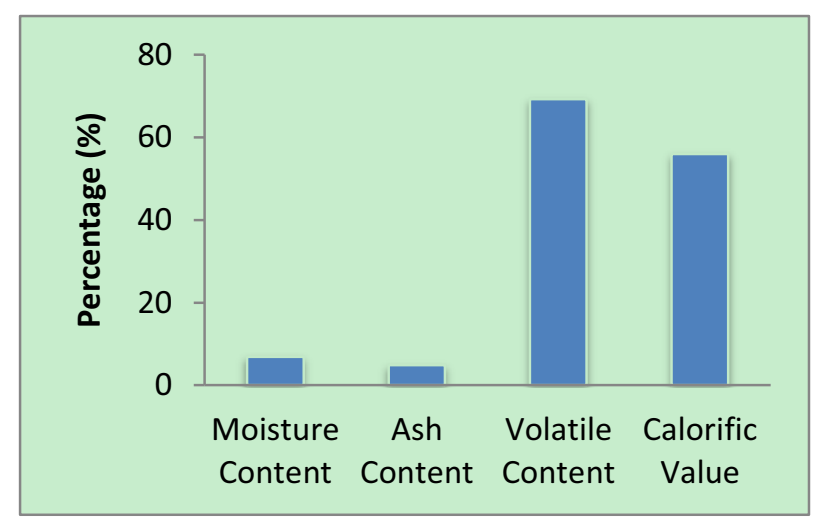

Figure 1. Moisture content, ash content, volatile content and calorific value of carbonaceous particles.

\subsection{Water Absorbency Properties}

The water absorbency of SAPs and carbonaceous-SAPs at various swelling time until $420 \mathrm{~min}$ is shown in Fig. 2(a). The absorption value of both samples (SAPs and carbonaceous-SAPs) were increased tremendously at the beginning of swelling time and reached a maximum value at certain period. From Fig. 2(a), it can be seen that the carbonaceous-SAPs had higher water absorbency value than the SAPs throughout the swelling time. The SAPs sample reached saturation or maximum absorbency value of $25 \mathrm{~g} / \mathrm{g}$ at $180 \mathrm{~min}(3 \mathrm{~h})$ whereas the carbonaceousSAPs reached maximum absorbency value of $40 \mathrm{~g} / \mathrm{g}$ at $300 \mathrm{~min}(5 \mathrm{~h})$. From this observation, it can be stated that the addition of carbonaceous particles improved the water absorbency of the samples but somehow reduce the absorbency rate as it required longer swelling time to achieve maximum absorption compare with the SAPs sample.
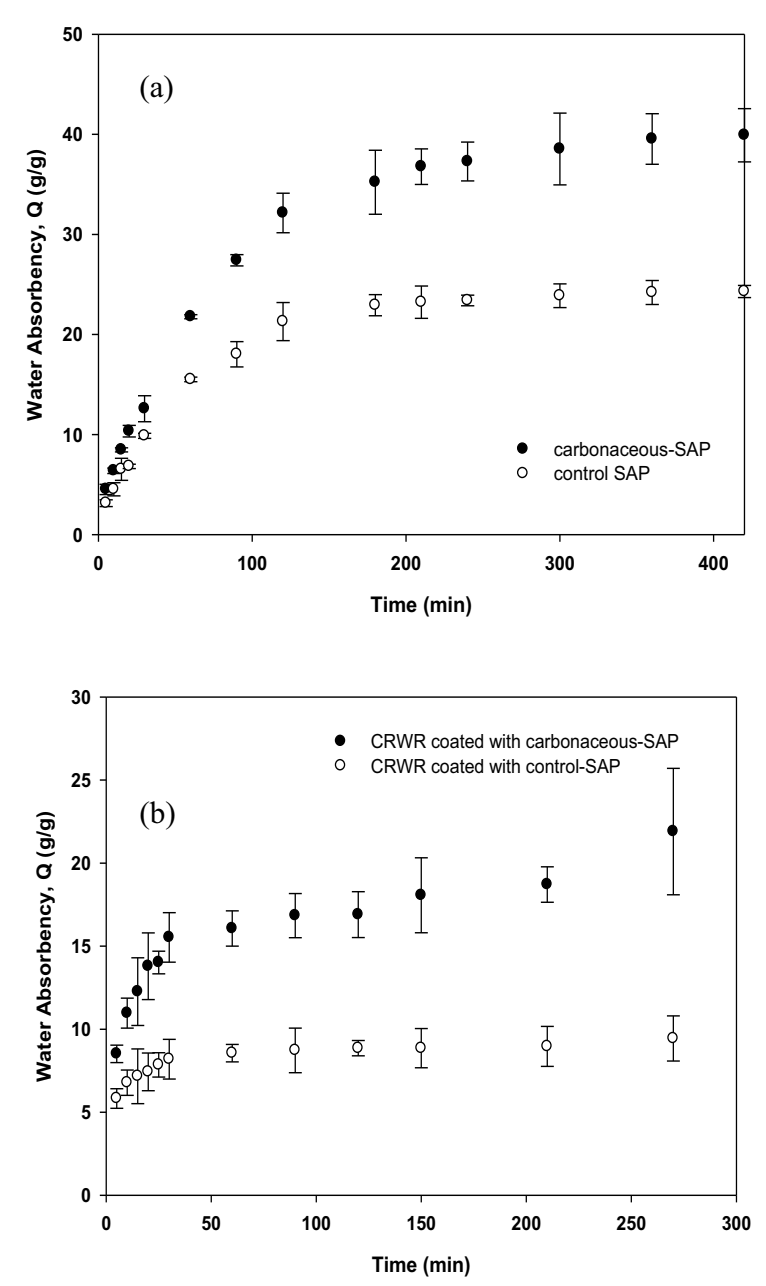

Figure 2. Water absorbency of (a) SAP and carbonaceous-SAP, (b) CRWR coated with SAP and carbonaceous-SAP.

According to Zangi et al., [16], urea fertilizer is easily dissolve in water and normally takes around 270 seconds to completely dissolve in water. Fig. 2(b) showed water absorbency of CRWR fertilizer coated with SAPs and carbonaceous-SAPs with time. From Fig. 2(b), it is clearly observed that CRWR fertilizer that coated with carbonaceous-SAPs show the higher water absorption value with slow water absorbency rate than CRWR coated with SAPs. CRWR fertilizer coated with SAPs achieved maximum point faster than the fertilizer with carbonaceous filler which is about $8 \mathrm{~g} / \mathrm{g}$ at $1 \mathrm{~h}$ meanwhile the CRWR fertilizer coated with carbonaceous-SAPs approached maximum value about $18 \mathrm{~g} / \mathrm{g}$ at $150 \mathrm{~min}$ or 2 h $30 \mathrm{~min}$. This observation can be related to the 
composition of coating layer. It was believed that the addition of carbonaceous filler that has hydrophilic properties increase the water uptake of the coating material. At the same time, the presence of this carbonaceous particles also act as barrier that slow down the diffusion rate of the water. The observation of water absorbency of CRWR fertilizers can be related to its morphology structure. Porous structure of carbaceous particles also results in the increase of water absorbency value. The presence of pores within the CRWR fertilizer coated with carbonaceous-SAPs allow the water to diffuse in and occupy the space [17]. This eventually cause the CRWR fertilizer coated with carbonaceousSAPs can store large amount of water compared to the CRWR fertilizer coated with SAPs.

\subsection{Water Retention Properties of CRWR in soil}

Some of the important soil physical conditions that influence the crop production are water capacity and water retention properties. The incorporation of carbonaceous particles could improved soil physical properties by increase aggregate stability and reduce bulk density which eventually affects the water retention properties of the soil.

Table 1. Comparison of Water Retention Properties of 1 wt.\% CRWR Fertilizer Coated Carbonaceous-SAP in Organic and Top Soil.

\begin{tabular}{|c|c|c|}
\hline \multirow{2}{*}{ Day } & \multicolumn{2}{|c|}{ Water Retention (\%) } \\
\cline { 2 - 3 } & CRWR in organic soil & CRWR in top soil \\
\hline 1 & 100.00 & 100.00 \\
\hline 3 & 94.24 & 92.28 \\
\hline 5 & 89.24 & 85.66 \\
\hline 7 & 84.03 & 79.04 \\
\hline 9 & 79.64 & 73.11 \\
\hline 11 & 75.71 & 67.88 \\
\hline 13 & 71.68 & 62.65 \\
\hline 15 & 67.61 & 57.12 \\
\hline 17 & 64.15 & 55.56 \\
\hline 19 & 62.11 & 51.94 \\
\hline 21 & 60.04 & 48.33 \\
\hline
\end{tabular}

Organic soil normally used as potting soil for plantation. It is the organic matter component of soil, consisting of plant and animal residues at various stages of decomposition, cells and tissues of soil organisms, and substances synthesized by soil organisms [18]. Meanwhile, the top soil in general is the top layer of the earth's surface. It is in dark brown colour and high in organic matter, which makes it very easy to till and fertilize ground for growing plants. It is comprised of the three main groups of organic matter which are humus, clay particles and sand. In this study, the effect of 1 wt. \% of CRWR fertilizer coated with carbonaceous-SAPs in two different soils on water retention properties were observed and summarized in Table 1. The obtained result in Table 1 shows that both CRWR coated with SAPs and carbonaceous-SAPs have capability to absorb and stored water before slowly released the nutrients with soil moisture [6]. By comparing the results in Table 1, it can also be seen that the water retention of CRWR fertilizer coated with carbonaceous-SAPs in top soil decreased faster than the organic soil. In $7^{\text {th }}$ day, the water retention of CRWR fertilizer in organic soil and top soil is $84.03 \%$ and $79.04 \%$, respectively. This results shows that the organic soil had higher water retention ability for CRWR fertilizer compared with top soil. According to El-Rahim [19], the water retention ability in soils is related to the way of soil in holding the water. There is two ways for soil holding water which are a film coating on soil particles and in the pore space between particles. Moreover, the soil porosity also could affect the water retention in soil. Large pore spaces between the soils could prevent water retention, where the water transpiration is quickly. This soil porosity are depends on soil texture and structure, where water can be held tighter in small pores than in large pores through capillary forces [19]. Therefore, organic soils with small pores can hold more water than top soil.

\subsection{Fourier Transform Infrared (FTIR) Spectrophometer}

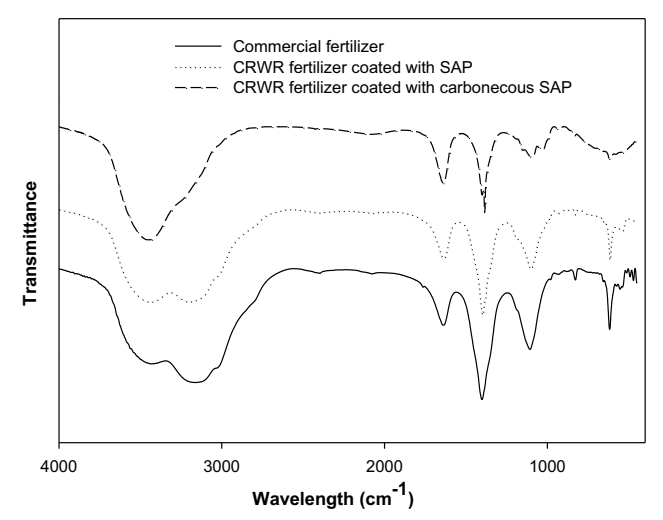

Figure 3. The IR spectrum of commercial fertilizer, CRWR fertilizer coated with SAP and CRWR fertilizer coated with carbonaceous-SAP.

Fig. 3 shows the peak of $\mathrm{O}-\mathrm{H}, \mathrm{C}=\mathrm{C}, \mathrm{C}-\mathrm{H}$ and $\mathrm{C}-\mathrm{O}$ bonds for commercial fertilizer and CRWR fertilizers coated with SAPs and carbonaceous-SAPs. Based on the Fig. 3, the commercial fertilizer had the highest wavelength peak at $3163 \mathrm{~cm}^{-1}$ which represents the carboxylic group, and the peaks at 1636,1402 and $1107 \mathrm{~cm}^{-1}$ indicate the presence of alkene, alkane and alcohol, phenol or ester groups respectively. Meanwhile, the spectrum for the CRWR fertilizer coated with SAP and carbonaceousSAPs shows the highest wavelength at $3436-3437 \mathrm{~cm}^{-1}$ representing $\mathrm{O}-\mathrm{H}$ bond, at $1638 \mathrm{~cm}^{-1}$ representing alkene group, and at $1384-1401 \mathrm{~cm}^{-1}$ representing alkane. Moreover, for the CRWR fertilizer coated with carbonaceous-SAPs, there is three wavelengths are close to one another at 1151,1104 and $1023 \mathrm{~cm}^{-1}$ that corresponding to the $\mathrm{C}-\mathrm{O}$ group from the carbonaceous filler. In this study, there is an intermolecular hydrogen bond formation between the fertilizer core and SAP monomers. The broad stretching band of hydroxyl groups 
(3600-3300 $\left.\mathrm{cm}^{-1}\right)$ is relating to the stretching $\mathrm{O}-\mathrm{H}$ from the intermolecular and intramolecular hydrogen bonds.

\subsection{Morphological Properties of SAP and CRWR}

The surface and cross sectional image of the two samples which were CRWR fertilizer coated with SAPs and carbonaceous-SAPs that were observed under SEM at magnification of 50x are shown in Fig. 4. Based on Fig. 4, the morphology of surface of both CRWR fertilizer coated with SAPs and carbonaceous-SAPs are loose and porous, with presence of holes and cracks of varying sizes which allowing the diffusion of water into the structure. According to $\mathrm{Wu}$ and Liu [15], CRWR fertilizer with course and porous surface could help the sample to absorb water quickly in large amount. The cross-section for the both CRWR fertilizers under SEM also reveal the presence of two layers as shown in Fig. 4. However, in this study, the presence of this two layers are not uniform in thickness due to the variety of SAPs powder used during the coating process.
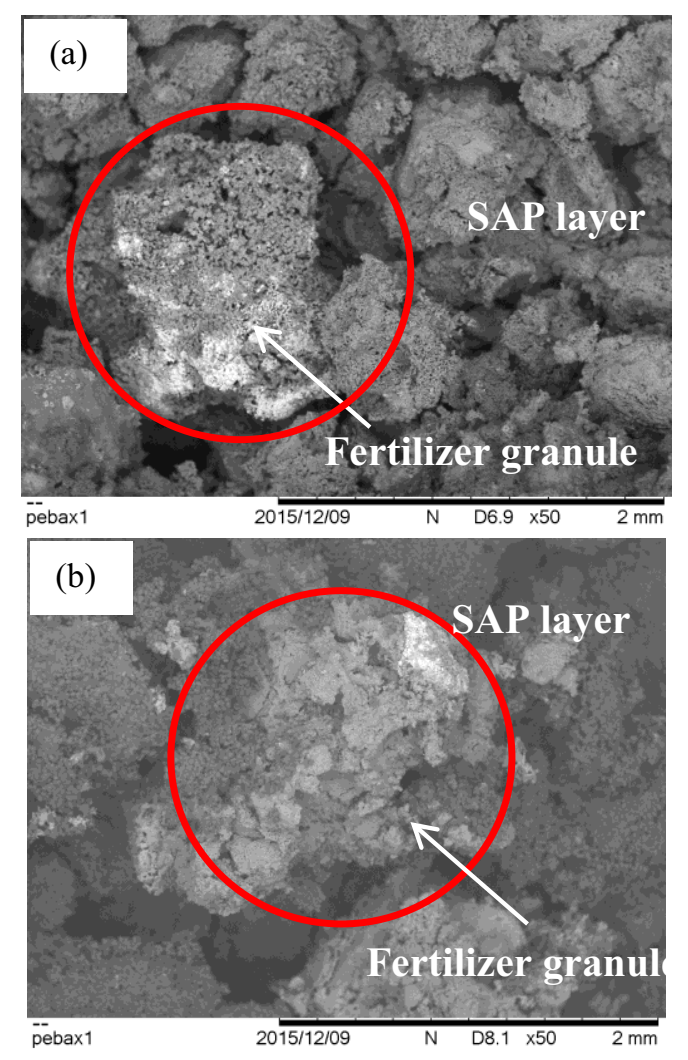

Figure 4. SEM of the cross-section of CRWR fertilizer coated with (a) SAP (b) carbonaceous-SAP.

\section{Conclusion}

In this study, the single coated of controlled release water retention (CRWR) fertilizer has been successfully synthesized via solution polymerization method. The presence of hydrophilic carbonaceous particles increased the water absorbency of the sample thus results in higher water absorbency of CRWR fertilizer coated with carbonaceous-SAPs. The obtained CRWR fertilizer coated with SAPs and carbonaceous-SAPs are loose and porous, with presence of holes that allowing the entry of water into the system and expands their size due to the storage of water at its outer layer. Result from FTIR analysis shows the presence of $\mathrm{O}-\mathrm{H}, \mathrm{C}=\mathrm{C}, \mathrm{N}-\mathrm{H}, \mathrm{C}-\mathrm{H}, \mathrm{C}$ $\mathrm{O}, \mathrm{C}-\mathrm{S}$ and $\mathrm{O}=\mathrm{C}=\mathrm{O}$ bonds that results in high water absorbency of CRWR fertilizer. Moreover, 1 wt \% CRWR fertilizer in organic soil had higher water retention ability compared with $1 \mathrm{wt} \%$ CRWR fertilizer in top soil. In conclusion, CRWR fertilizer gave a significant influence on the performance of water absorbency and controlled of nutrients release rate as well as function as water retention in soil.

\section{References}

1. Istikoma, Quratul-Ain, A. D. Abdul Rahman, (2015). The Transformation of Agriculture Based Economy to an Industrial Sector through Crowd Sourcing In Malaysia, International Journal of Computer Science and Information Technology Research, vol. 3, Issue 1, pp34-41.

2. S. Savci, (2012). An Agricultural Pollutant: Chemical Fertilizer. International Journal of Environmental Science and Development.

3. Y. Munusamy, Y. T. Jeng, C. S. Yong, (2013). Development of controlled release fertilizer using biodegradable superabsorbent polymers for plantations in Malaysia.

4. S. Al-Zahrani, (1999). Controlled-release of fertilizers: modelling and simulation. International Journal of Engineering Science, vol. 37, no. 10, pp.1299-1307.

5. M. Guo, M. Liu, Z. Hu, F. Zhan, L. Wu, (2005). Preparation and properties of a slowrelease NP compound fertilizer with superabsorbent and moisture preservation, Journal of Applied Polymer Science, pp2132-2138.

6. L. Wu, M. Liu, R. Liang, (2008). Preparation and properties of a double-coated slow-release NPK compound fertilizer with superabsorbent and waterretention. Bioresource Technology 99, pp547-554.

7. A. Shaviv, (2005). Controlled release fertilizers. IFA International Workshop on Enhanced-Efficiency Fertilizers.

8. M. Liu, T. Guo, (2001). Preparation and Swelling Properties of Crosslinked Sodium Polyacrylate, Journal of Applied Polymer Science 82, pp15151520.

9. H. A. El-Rahim, E. S. Hegazy, H. El-Mohdy, (2004). Radiation synthesis of hydrogels hydrogels to enhance sandy soils water retention and increase plant performance, Journal of Applied Polymer Science, pp.1360-1371.

10. B. Glaser, (2002). Ameliorating Physical and Chemical Properties of Highly Weathered Soils in the Tropics with Charcoal: A review, Biological and Fertiliser of Soils, ISSN0178-2762, 35(4), 219-230.

11. S. Jamari, S. Ghazali, W. Yaacob, (2015). Effect of Superabsorbent Polymer Composite Filled Carbon 
Fiber Towards the Germination of Abelmoschus Esculentus, JOAAT, 2 (2), pp156-159.

12. H. K. Nsamba, (2015). Sustainable Technologies for Small-Scale Biochar Production : A Review, Journal of Sustainable Bioenergy Systems, 5. , 10-31 .

13. N. Mohamad, A. H. Nor Nadiah, A. R. Jeefferie, D. Mohd Fairuz, (2011). Effect of Chitosan Gelatinization Temperature on Water Absorption and Water Retention of Chitosan Based Urea Fertilizer.

14. A. B. Pitaloka, A. H. Saputra, A. H., M. Nasikin, (2013). Water Hyacinth for Superabsorbent Polymer Material. World Applied Sciences Journal, pp747754.

15. L. Wu, M. Liu, (2008). Preparation and properties of chitosan-coated NPK compound fertilizer with controlled-release and water-retention. Carbohydrate Polymers, 72 (2), pp240-247.
16. R. Zangi, R. Zhou, B. J. Berne, (2009). Urea's action on hydrophobic interactions. Journal of American Chemical Society, 131: pp1535-1541.

17. Z. Guohua, L. Ya, F. Cuilan, Z. Min, Z. Caiqiong, C. Zongdao, (2006). Water resistance, mechanical properties and biodegradability of methylatedcornstarch/poly(vinyl alcohol) blend film, Polymer Degradation and Stability, 91,pp703-711.

18. N. C. Brady, R. R. Weil, The nature and properties of soil, $12^{\mathrm{th}}$ ed. Prentice Hall, Inc., Upper Saddle River, NJ., 1999.

19. H. A. El-Rahim (2006). Characterization and possible agricultural application of polyacrylamide/sodium alginate crosslinked hydrogels prepared by ionizing radiation, $J$ Appl Polym Sci 101: pp3572-3580. 